\title{
The ICAM-1 Gly241Arg Polymorphism is Not Associated With Polycystic Ovary Syndrome - Results from a Case Control study in Kashmir, India
}

\author{
Syed Douhath yousuf ${ }^{1}$, Mohammad Ashraf Ganie², Mohammad Afzal Zargar'1, \\ Tabasum Parvez ${ }^{3}$, Fouzia Rashid ${ }^{1 *}$
}

\begin{abstract}
Background: Polycystic ovary syndrome (PCOS) is considered to be a multifactorial disorder resulting from the interaction of several predisposing and protective genetic variants. PCOS is associated with low-grade chronic inflammation. Elevated levels of inflammatory markers including intercellular adhesion molecule-1 (ICAM-1) are demonstrated in women with PCOS. Recent evidence indicates a significant linkage between a locus on chromosome 19p13 and multifactorial diseases that have an inflammatory component. The aim of the study was to assess the possible association of Gly241Arg polymorphism of ICAM-1 gene located on chromosome 19p13 in determining risk of PCOS in Kashmiri women. Materials and Methods: Gly241Arg SNP in DNA from peripheral blood leukocytes of 220 PCOS cases and 220 age matched non-PCOS healthy controls was analysed using allel specific PCR. Results: The genotype and allele frequency distributions of Gly241Arg SNP showed insignificant difference between the PCOS cases and control women, indicating no role of this SNP in PCOS susceptibility. The odds ratio for Arg/Arg genotype was $0.87(95 \% \mathrm{CI}=0.32-2.3)$ [P=0.79], for Gly/Arg genotype was $0.98(95 \% \mathrm{CI}=0.66-1.47)[\mathrm{P}=1]$ and for $\mathrm{Arg} / \mathrm{Arg}+\mathrm{Gly} / \mathrm{Arg}$ genotype was $0.97(95 \% \mathrm{CI}=0.65-1.45)[\mathrm{P}=0.92]$. The genotypic frequencies of ICAM-1codon 241 showed statistically insignificant difference between cases and controls $\left(\chi^{2}=0.07 ; p=0.96\right)$ Nor the studied polymorphism was found to affect clinical and laboratory parameters significantly. Conclusions: Although Gly241Arg polymorphism have not shown significant association with PCOS. Further, specifically designed studies on large cohorts are required to conclusively establish any role of ICAM-1 gene polymorphisms in PCOS in our study.
\end{abstract}

Keywords: Gly241Arg - ICAM-1 - polycystic ovary syndrome - polymorphism - SNP

Asian Pac J Cancer Prev, 17 (3), 1583-1588

\section{Introduction}

The polycystic ovary syndrome (PCOS) is a common and complex endocrinopathy affecting 3-10\% of women of reproductive age (Azziz et al., 2004; Nidhi et al., 2011) and is characterized by hyperandrogenism, chronic anovulation and polycystic ovarian morphology on ultrasonography (Rosenfield, 2015). It may be associated with increased risk of endometrial cancer (Shen et al., 2015). Insulin resistance and its compensatory hyperinsulinemia is a central feature of PCOS (Asante et al., 2015).

Insulin resistance has been increasingly recognised as having a key role in chronic inflammation and endothelial dysfunction, which represent an early sign of atherosclerosis (Prieto et al, 2014). Adhesion molecules are one of the main markers of low-grade inflammation and endothelial dysfunction (Blankenberg et al., 2003). Intercellular adhesion molecule-1 (ICAM-1,
CD54) is a member of immunoglobulin superfamily of adhesion molecules. It is expressed on the surface of the endothelium cells, smooth muscle cells, macrophages and activated lymphocytes. ICAM-1 plays an important role in the adhesion of circulating leukocytes to the blood vessel wall and transendothelial migration to vascular intima (Hayflick et al., 1998). ICAM-1 binds to $\beta 2$ integrins of leukocytes, leukocyte function associated antigen-1 (LFA1 , Integrin $\alpha \mathrm{L} \beta 2$ ) and macrophage antigen -1 (MAC-1, Integrin $\alpha \mathrm{M} \beta 2$ ) (Springer, 1990). Fibrinogen could also be a ligand for ICAM-1 (Languino et al., 1993). There are soluble forms of adhesion molecules in circulation that allows assessment of the protein's concentration.During the last decade, several studies have analyzed the serum ICAM-1 levels in women with PCOS in an attempt to link PCOS with risk of cardiovascular diseases (CVD) and it has been reported that women with PCOS have significantly increased ICAM-1 concentrations (Nasiek 
et al., 2004; Vrbikova, 2005; Diamanti-Kandarakis et al., 2006; Gonzalez et al., 2009) suggesting ICAM-1 as a marker of low-grade inflammation, and a predictor of disease related to PCOS.

Genome-wide scans have predicted that PCOS susceptibility genes may reside over a broad region of chromosome 19p13.2 (Urbanek et al., 2005). ICAM-1 gene is located in 19p13.3-p13.2 chromosomal region. A common genetic polymorphism (rs1799969) at codon 241 in exon 4 of ICAM- 1 gene resulting in substitution of an $\mathrm{G}$ with an A nucleotide and replaces Glycine $(\mathrm{G})$ with a Arginine (R) in ICAM-1 gene has been described (Vora DK et al., 1994). Limited data are available on Gly241 Arg polymorphism of ICAM-1 gene and its relationship with development of PCOS especially among Indian women. Since polymorphism of ICAM-1 are common genetic variation, several polymorphisms of ICAM-1 gene have been studied in number of inflammatory diseases like peripheral occlusive arterial disease (Flex et al., 2007), inflammatory bowel disease (Song et al., 2015), diabetes type 1 (Nejentsev et al., 2003), diabetes mellitus (Petrovic et al., 2008) and coronary artery disease (Chou et al., 2015). Therefore, the exon 4 of ICAM-1 gene represents a strong positional and biological candidate for the susceptibility to the development of inflammatory and metabolic diseases which may include PCOS. In the present study the genetic association between Gly241Arg polymorphism on exon 4 of ICAM-1 gene and incidences of PCOS in kashmiri women was examined.

\section{Materials and Methods}

\section{Study population}

220 women with established PCOS and 220 healthy women were studied. The Rotterdam criteria (2003) was used for the diagnosis of PCOS which states 2 of the 3 features needs to be present to make the diagnosis of PCOS. These features includes (1) Oligo- or anovulation (< eight menstrual cycles in the presenting year) (2) Clinical and/or biochemical signs of hyperandrogenism and (3) Polycystic ovaries (either 12 or more follicles measuring 2-9 $\mathrm{mm}$ in diameter, or an ovarian volume of $>10 \mathrm{~cm}^{3}$ ), with the exclusion of other etiologies (Non classic congenital adrenal hyperplasia, androgensecreting tumors, cushing's syndrome). Non classic congenital adrenal hyperplasia (NCAH), cushing's syndrome, thyroid dysfunction, hyperprolactinemia, and androgen-producing tumors were ruled out by doing relevant investigation. All the PCOS patients belonged to Department of Endocrinology Sher-i-kashmir Institute of Medical Sciences (SKIMS) Srinagar, Kashmir. The nonPCOS group represented 220 apparently normal women having regular menstrual cycles (21-35d), displaying no evidence of clinical/biochemical hyperandrogenism, and having normal ovarian morphology on trans-abdominal ultrasonography. Controls were collected from various medical camps organised at colleges and at university of Kashmir. Women consuming any hormonal preparations or drug(s) known or suspected to affect reproductive or metabolic functions within 6 months of the study entry, or those having known diabetes mellitus instead, renal, hepatic, or cardiac dysfunction were also excluded from the study. PCOS cases and non PCOS healthy controls of same age group were preferentially selected and enrolled in the study. The study protocol was approved by the Institutional Ethics Committee and written informed consent was obtained from all the participants.

\section{Anthropometric and systemic examination}

All women underwent anthropometric assessment like measurement of height, weight, waist-hip circumference ratio and detailed systemic examination. Hirsutism assessment was done using modified Ferriman-Gallwey score by counting nine specified body areas. A score of $>$ 8 out of a total of 36 was taken as significant.

\section{Biochemical Analysis}

Biochemical analysis includes oral glucose tolerance test(OGTT), insulin,triglyceride(TG), low density lipoprotein(LDL), high density lipoprotein(HDL) and total cholesterol.

\section{Calculations}

Insulin resistance was assessed by means of the fasting glucose to insulin ratio (FGIR), homeostasis model assesment insulin resistance index (HOMA-IR) and quantitative insulin sensitivity check index (QUICKI). The FGIR values were calculated as fasting glucose $(\mathrm{mg} / \mathrm{dL}) /$ fasting insulin $(\mu \mathrm{IU} / \mathrm{mL})$. The HOMA index was calculated as [fasting insulin $(\mu \mathrm{IU} / \mathrm{mL}) \mathrm{x}$ fasting glucose $(\mathrm{mg} / \mathrm{dL})] / 405$. The QUICKI was calculated as $1 /$ [log fasting insulin $(\mu \mathrm{IU} / \mathrm{mL})+\log$ fasting glucose (mg/dL)]. High HOMA-IR, low QUICKI and low FGIR scores denote insulin resistance (low insulin sensitivity). Body mass index (BMI) was calculated as body weight (kg) divided by body height squared (m2).

\section{Hormonal analysis}

Hormonal analysis included; LH, FSH, Testosterone, 17-OHP and cortisol. 17 OHP to rule out non classical congenital adrenal hyperplasia and cortisol to rule out cushing's syndrome. T4 - to rule out hyperthyroidism, TSH - to rule out hypothyroidism, PRL- to rule out prolactinoma. The sampling was arranged in such a way so that the sample for $\mathrm{LH}, \mathrm{FSH}, 17-\mathrm{OHP}$ and testosterone was collected on $3^{\text {rd }}$ to $7^{\text {th }}$ day of the follicular phase of either spontaneous or progesterone induced menstrual cycle.

\section{Molecular Analysis of Gly241Arg Polymorphism of ICAM-1 Gene}

DNA was extracted from peripheral leukocytes according to Phenol-Chloroform method. The quality of the resulting genomic DNA was stringently assessed by low percentage agarose gel electrophoresis. The concentration of the DNA obtained was measured in a Evolution 201 UV-Vis Spectrophotometer (Thermo Fisher Scientific) at $260 \mathrm{~nm}$ wavelength and the purity of DNA was checked by using A260/ A280 ratio.

\section{ICAM-1 Codon 241 Genotyping}

An allele specific PCR method was used to amplify a 137 bp fragment of exon 4 of ICAM-1 gene using 
ICAM-1 Gly241Arg Polymorphism is Not Associated with Polycystic Ovary Syndrome in Kashmir, India.

the appropriate primers. The primer sets consisted of Primer G: 5GTGGTCTGTTCCCTGGACG3; Primer R: 5GTGGTCTGTTCCCTGGACA3 Common primer: 5GCGGTCACACTGACTGAGGCCT3. For each individual two distinct PCR reactions were performed, one with primers $\mathrm{G}$ and the common primer and another with primers $\mathrm{R}$ and the common primer. Approximately $300 \mathrm{ng}$ genomic DNA was amplified in a total volume of $25 \mu$ of the reaction mixture containing $2.5 \mu$ l of 10X PCR buffer, $2 \mu \mathrm{l}$ of $\mathrm{Mgcl} 2,0.5 \mu \mathrm{l}$ of $10 \mathrm{mM}$ dNTP mix, $0.5 \mu \mathrm{l}$ of forward Primer (G) (20nm), $0.5 \mu$ l of forward Primer (R) (20nm), $0.5 \mu \mathrm{l}$ of common (reverse) Primer (20nm), $0.3 \mu \mathrm{l}$ of Taq DNA polymerase (1U) $3.0 \mu$ l of Genomic DNA, $15.2 \mu \mathrm{l}$ of deionized water to make total volume equal to 25.0 $\mu$ l. PCR amplification was done using touch-down method including an initial denaturation at $94^{\circ} \mathrm{C}$ for 5 min and two loops of amplification. Loop one included: 10 cycles of $94^{\circ} \mathrm{C}$ for $20 \mathrm{~s}, 65^{\circ} \mathrm{C}$ for $20 \mathrm{~s}, 72^{\circ} \mathrm{C}$ for $20 \mathrm{~s}$, Loop two included: 20 cycles of $94^{\circ} \mathrm{C}$ for $20 \mathrm{~s}, 61.5^{\circ} \mathrm{C}$ for $20 \mathrm{~s}$, $72^{\circ} \mathrm{C}$ for $20 \mathrm{~s}$. Final extension was performed at $72^{\circ} \mathrm{C}$ for $5 \mathrm{~min}$. The amplified PCR products of $137 \mathrm{bp}$ were run on $2 \%$ ethidium bromide stained agarose gel and visualized under UV transilluminator. (Figure 1)

\section{Statistical analysis}

Data was statistically analysed for mean values and standard deviations (SD) in Microsoft Office Excel. ANOVA and unpaired Student t-tests were used to compare the means of variables. Allel and genotype frequencies in the case and control groups were compared using Chi-square and Fischer exact tests. Statistical significance was set at $\mathrm{P}<0.05$. Statistical analyses were

Table 1. Clinical and Laboratory Characteristics of Cases and Controls

\begin{tabular}{|c|c|c|c|c|c|}
\hline \multirow[t]{2}{*}{ VARIABLES } & \multicolumn{2}{|c|}{$\begin{array}{l}\text { CASES } \\
\mathrm{N}=220\end{array}$} & \multicolumn{2}{|c|}{$\begin{array}{c}\text { CONTROLS } \\
\mathrm{N}=220 \\
\end{array}$} & \multirow[t]{2}{*}{ P VALUE } \\
\hline & MEAN & SD & MEAN & SD & \\
\hline Age (years) & 23 & 4.82 & 22.9 & 3.58 & $0.86(\mathrm{NS})$ \\
\hline FG score & 13 & 3.23 & 7 & 2.33 & 0.0001 \\
\hline BMI ( kg/m2) Cycles per year & 23.8 & 3.03 & 23.4 & 3.31 & $0.14(\mathrm{NS})$ \\
\hline Waist Hip Ratio Cases; & & & & & \\
\hline mean $=7.2 \mathrm{SD}=3.55$ & 0.87 & 0.02 & 0.84 & 0.05 & $<0.00$ \\
\hline LH (IU/1) Controls; mean= 11.5 SD=4.22 & 8.06 & 1.97 & 6.13 & 1.22 & $<0.00$ \\
\hline FSH (IU/1) P value $=<0.0001$ & 6.66 & 1.23 & 6.94 & 1.99 & $0.07(\mathrm{NS})$ \\
\hline Testosterone (ng/dl) & 85.2 & 15.8 & 32.8 & 11.2 & $<0.00$ \\
\hline Blood glucose Fasting (mg/dl) & 88 & 12 & 87.7 & 12.8 & $0.75(\mathrm{NS})$ \\
\hline Blood glucose $1 \mathrm{hr}(\mathrm{mg} / \mathrm{dl})$ & 136 & 17.8 & 131.2 & 15.5 & 0.0002 \\
\hline Blood glucose $2 \mathrm{hr}(\mathrm{mg} / \mathrm{dl})$ & 102.3 & 19.4 & 94.1 & 20.2 & $<0.00$ \\
\hline Insulin Fasting $(\mu \mathrm{IU} / \mathrm{ml})$ & 20.8 & 5.22 & 10.8 & 7.72 & $<0.00$ \\
\hline FGIR & 4.44 & 1.16 & 7.85 & 3.06 & $<0.00$ \\
\hline QUICKI & 0.3 & 0.01 & 0.33 & 0.09 & $<0.00$ \\
\hline HOMA-IR & 4.55 & 1.35 & 2.14 & 1.23 & $<0.00$ \\
\hline Cholesterol(mg/dl) & 181.2 & 20.2 & 158 & 17.6 & $<0.00$ \\
\hline Triglycerides(mg/dl) & 151.2 & 22.6 & 104 & 20.7 & $<0.00$ \\
\hline HDL(mg/dl) & 43 & 6.21 & 48 & 7.81 & $<0.00$ \\
\hline $\mathrm{LDL}(\mathrm{mg} / \mathrm{dl})$ & 119 & 16.1 & 93 & 18.3 & $<0.00$ \\
\hline
\end{tabular}

$\mathrm{NS}=$ Statistically Non significant $(\mathrm{P}>0.05) ; \mathrm{SD}=$ Standard Deviation; BMI, Body Mass Index; FGIR, fasting glucose insulin ratio; FG Score, Ferrimen Gallwey score. FSH, follicular stimulating hormone; HDL, High density lipoprotein; HOMA-IR, Homeostasis Model Assessment Insulin resistance index; LDL, Low density Lipoprotein; LH, luteinizing hormone; QUICKI, quantitative insulin sensitivity index.

Table 2. Genotypic and Allelic Frequencies of ICAM-1 Gene Codon 241 among Cases \& Controls and their Association with Risk of PCOS

\begin{tabular}{|c|c|c|c|c|c|}
\hline $\begin{array}{c}\text { ICAM-1Gene } \\
\text { Codon } 241\end{array}$ & Variants & Cases $(\mathrm{N}=220)$ & Controls $(\mathrm{N}=220)$ & $\begin{array}{c}\text { OR }(95 \% \mathrm{CI}) ; \mathrm{P}^{*} \\
\text { Value } \\
\end{array}$ & $\begin{array}{c}\chi^{2} ; \text { P Value } \\
\text { (Overall) }\end{array}$ \\
\hline \multirow{4}{*}{$\begin{array}{c}\text { Genotypic } \\
\text { Frequencies (N) }\end{array}$} & Gly/Gly (Wild) & $73(33.1 \%)$ & $72(32.7 \%)$ & 1 & \multirow{4}{*}{$0.07 ; 0.96$} \\
\hline & $\begin{array}{c}\text { Gly/Arg } \\
\text { (Hetereozygous) }\end{array}$ & $139(63.1 \%)$ & $139(63.1 \%)$ & $\begin{array}{c}0.98(0.66-1.47) \\
{[1]}\end{array}$ & \\
\hline & Arg/Arg (variant) & $8(3.63 \%)$ & $9(4.09 \%)$ & $\begin{array}{c}0.87(0.32-2.3) \\
{[0.79]} \\
\end{array}$ & \\
\hline & Gly/Arg+ Arg/Arg & $147(66.8 \%)$ & $148(67.2 \%)$ & $\begin{array}{c}0.97(0.65-1.45) \\
{[0.92]} \\
\end{array}$ & \\
\hline \multirow{2}{*}{$\begin{array}{l}\text { Allelic Frequency } \\
\qquad(2 \mathrm{~N})\end{array}$} & Gly (G allele) & $285(64.8 \%)$ & $283(64.3 \%)$ & $1.0^{*}$ & - \\
\hline & Arg (R allele) & $155(35.2 \%)$ & $157(35.7 \%)$ & $\begin{array}{c}0.98(0.74-1.29) \\
0.88 \\
\end{array}$ & - \\
\hline
\end{tabular}

$\mathrm{P}^{*}=$ Pearsons $\mathrm{P}$ value 
Table 3. Clinical and Laboratary Parameters of Cases in Accordance with their Genotypes of the ICAM1 Gly241Arg Polymorphism

\begin{tabular}{|c|c|c|c|c|c|c|c|}
\hline \multirow[t]{2}{*}{ Variable } & \multicolumn{2}{|c|}{ Arg/Arg } & \multicolumn{2}{|c|}{ Gly/Arg } & \multicolumn{2}{|c|}{ Gly/Gly } & \multirow[t]{2}{*}{ P-value } \\
\hline & Mean & SD & Mean & $\mathrm{SD}$ & Mean & SD & \\
\hline $\mathrm{BMI} \mathrm{Kg} / \mathrm{m}^{2}$ & 24.4 & 2.07 & 24 & 3.21 & 23.5 & 2.75 & $0.46 \mathrm{NS}$ \\
\hline Waist Hip Ratio & 0.86 & 0.03 & 0.87 & 0.02 & 0.87 & 0.02 & $0.30 \mathrm{NS}$ \\
\hline Testosterone ng/dl & 84.5 & 13.2 & 83.5 & 14.9 & 88.5 & 17.3 & $0.08 \mathrm{NS}$ \\
\hline Glucose $0 \mathrm{Hr} \mathrm{mg} / \mathrm{dl}$ & 92.8 & 17.1 & 86.8 & 11.3 & 89.8 & 12.5 & $0.11 \mathrm{NS}$ \\
\hline \multicolumn{8}{|l|}{ Glucose $0 \mathrm{hr}$ as, } \\
\hline Fasting Glucose. & 102.2 & 5.79 & 102.6 & 21 & 102.8 & 17.2 & $0.99 \mathrm{NS}$ \\
\hline \multicolumn{2}{|c|}{ Insulin $0 \mathrm{hr}$ as Fasting insulin 21} & 4.84 & 20.9 & 5.34 & 20.6 & 5.12 & $0.93 \mathrm{NS}$ \\
\hline GIR as FGIR & 4.71 & 1.62 & 4.4 & 1.2 & 4.55 & 1.06 & $0.55 \mathrm{NS}$ \\
\hline HOMA as HOMA-IR & 4.76 & 1.3 & 4.51 & 1.34 & 4.63 & 1.41 & $0.75 \mathrm{NS}$ \\
\hline QUICKI & 0.306 & 0.01 & 0.309 & 0.01 & 0.308 & 0.01 & $0.74 \mathrm{NS}$ \\
\hline Cholesterol mg/dl & 186.9 & 18.8 & 180 & 20.9 & 182.8 & 19.1 & $0.46 \mathrm{NS}$ \\
\hline $\mathrm{TG} \mathrm{mg} / \mathrm{dl}$ & 149 & 24.6 & 151.1 & 22.9 & 151.6 & 22.3 & $0.95 \mathrm{NS}$ \\
\hline HDL mg/dl & 45.6 & 5.69 & 42.6 & 6.78 & 43 & 4.74 & $0.41 \mathrm{NS}$ \\
\hline LDL mg/dl & 132.2 & 15.4 & 118.6 & 15 & 118.3 & 17.8 & $0.06 \mathrm{NS}$ \\
\hline
\end{tabular}

*NS=Statistically Non significant (P>0.05); SD, (COMMA) Standard Deviation; BMI, Body Mass Index; FGIR, fasting glucose insulin ratio; HDL, High density lipoprotein; HOMA-IR, Homeostasis Model Assessment Insulin resistance index; LDL, Low density Lipoprotein; QUICKI, quantitative insulin sensitivity index

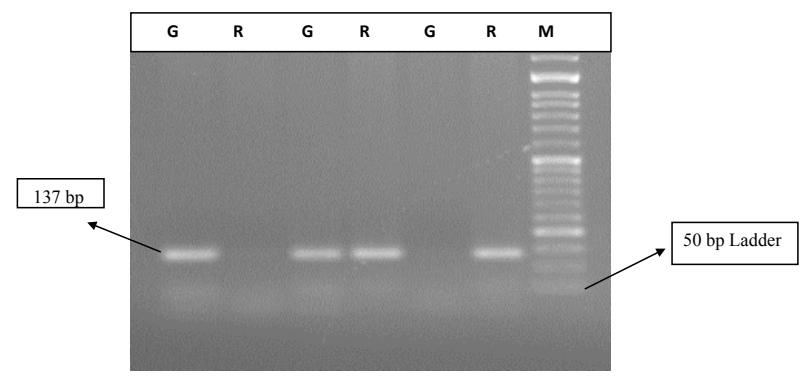

Figure 1.137 bp PCR products of codon 241 Gly(G) to $\operatorname{Arg}(R)$ substitution in ICAM-1 gene. G/G homozygote case in lane 1\&2, GR heterozygote case in lane $3 \& 4$ and $R / R$ homozygote case lane 5\&6. DNA size marker (50bp) in the last lane M. (2\% Agarose)

performed using SPSS and vassarstats online software

\section{Results}

Clinical and laborator characteristics of women with PCOS and control women are summarized in Table 1. The mean age of case and control women was comparable

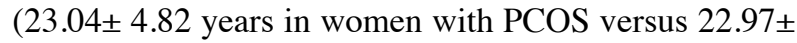
3.58 years in women without PCOS; $\mathrm{p}=0.862$ ) and was BMI (23.87 \pm 3.03 in PCOS group 23.43 \pm 3.31 in control group; $\mathrm{p}=0.146)$. FG score, cholesterol, triglycerides, LDL, HDL, total testosterone, fasting Insulin, FGIR, HOMA IR, and QUICKI showed significant differences between PCOS group compared to control group $(\mathrm{p}<0.0001)$. There was no significant difference in mean values of age, BMI, fasting glucose, and FSH among women with PCOS as compared to controls

All PCOS cases and controls were genotyped for the ICAM-1 codon 241 SNP. ICAM1 GG (Gly/Gly) represents homozygous wild-type, RR (Arg/Arg) represents homozygous variant type, GR (Gly/Arg) represents heterozygous genotype (Figure 1). All the studied genotypes were almost equally distributed among cases and controls and the distribution was statistically insignificant.

The genotypic distributions of ICAM-1 Gly241Arg polymorphism for cases and controls are shown in Table 2. The odds ratio (OR) for Arg/Arg genotype was 0.87 (95\% CI=0.32-2.3) $[\mathrm{P}=0.79]$, for Gly/Arg genotype OR was $0.98(95 \% \mathrm{CI}=0.66-1.47)[\mathrm{P}=1]$ and for $\mathrm{Arg} / \mathrm{Arg}$ +Gly/Arg genotype OR was 0.97 (95\% CI=0.65-1.45) $[\mathrm{P}=0.92]$. The allelic frequency revealed statistically insignificant and almost equal distribution of $\mathrm{R}$ allel among cases and controls with $\mathrm{OR}=0.98$ (95\% CI=0.741.29); $\mathrm{P}=0.88$. The genotypic frequencies of ICAM-1 codon 241 showed a insignificant difference between cases and controls $\left(\chi^{2}=0.07, \mathrm{p}=0.96\right)$. The genotypic and allelic distributions of ICAM-1 Gly241Arg polymorphism for cases and controls are shown in Table 2. Furthermore the association between polymorphism with that of the clinical and laboratory parameters was also carefully analysed. However, we did not find any significant association ( $\mathrm{P}>0.05$ ) with any of the PCOS characteristics-shown in Table 3.

\section{Discussion}

In our study the objective was to find out the possible association between Gly241 Arg polymorphism of ICAM-1 gene with risk of developing PCOS in Kashmiri women. Our results revealed that there was no difference in the distribution of genotypic and allelic frequencies of Gly241Arg genotypes between cases and controls, thereby, suggesting that the polymorphism in this codon may not be associated with the risk of PCOS in our population. Furthermore the association between polymorphism with that of the clinical and laboratory parameters was also carefully analysed. However, we did not find any significant association $(\mathrm{P}>0.05)$ with any of the PCOS characteristic. With respect to ICAM1 Gly241Arg polymorphism our negative findings are 
ICAM-1 Gly241Arg Polymorphism is Not Associated with Polycystic Ovary Syndrome in Kashmir, India.

similar to those reported by Vural et al. (2011), Hazwanie et al. (2015) and Ojeda et al. (2015). The results of these studies highlighted no importance and no possible impact of genetic polymorphism of ICAM-1 (Gly241Arg) gene towards predisposition to PCOS. Moreover no association of the Gly241Arg polymorphism of ICAM1 gene with the clinical or laboratory parameters of the syndrome was observed in a study conducted by vural, again indicating that it is unlikely that this polymorphism plays a major role in determining susceptibility to PCOS.

Gly241Arg polymorphism is due to the substitution of a $\mathrm{G}$ with an A nucleotide at codon 241 of exon 4 in ICAM-1 gene, which replaces an glycine $(G)$ by a arginine (R) in the 3rd domain (D3) of the extracellular portion of ICAM-1 molecule. MAC-1 (CD11b) molecule, on the surface of leukocytes, interacts with D3 segment of ICAM-1 molecule. In the absence of D3 segment, ICAM-1 and MAC-1 will not interact. It seems that $\mathrm{G} \rightarrow \mathrm{A}$ mutation decreases the affinity of MAC- 1 for ICAM-1. The unbound ICAM-1 has inhibitory effects on the expression of ICAM-1 gene resulting in decreased levels of ICAM-1 in the blood (Mc Glinchey PG et al., 2004). Moreover, a functional study was performed which revealed that the $\mathrm{G} 241$ haplotype is associated with greater cell surface expression of ICAM-1, which in turn leads to greater adhesion of leukocytes to damaged endothelium and explains the possible association between chronic inflammatory diseases and ICAM-1 polymorphism (Holder et al., 2008). The few studies that addressed the association of variants in the genes encoding adhesion endothelial molecules with PCOS rendered conflicting results (Lee et al., 2008; Kanmaz-Ozer et al., 2012). Limited studies have been conducted on the association of Gly241Arg ICAM-1 gene polymorphism with development of PCOS which restricts the comparision of our study to very few studies of this nature. However several investigators have examined the genetic association between Gly241Arg ICAM-1 gene polymorphism and chronic inflammatory diseases which can provide indirect evidences for our study. Among Polish Caucasian patients with multiple sclerosis, the distribution of the Gly241 Arg polymorphism was not significant (Mycko et al., 1998). In Italian patients with either polymyalgia rheumatic or giant cell arteritis, the frequency of the Arg241 allele was significantly higher than in controls (polymyalgia rheumatic/giant cell arteritis $12.9 \%$ v $3.1 \%$ in controls) (Salvarani C et al., 2000) Gly241 Arg polymorphism was not identified among Palestinian and Jordanian patients with Behçet's disease (Verity et al., 2000). These results are contradictory and so the significance of this gene may differ according to the type of inflammatory disease. Also different populations represent different gene pools, suggesting that gene-disease associations can be expected to vary between populations due to the differences in a complex genetic background.

To the best of our knowledge, this is the first study regarding the association between ICAM-1 Gly241Arg polymorphism and PCOS susceptibility in Kashmir valley. From our results we concluded that there is not any association between Gly241Arg polymorphism and susceptibility to PCOS. Additionally, there is not a significant difference among genotypes of Gly241Arg in mean values of various clinical and laboratory (hormonal, insulin resistance and lipid profile) parameters.

In conclusion: our study neither the RR genotype nor the GG genotype was associated with PCOS, and therefore the Gly241Arg polymorphism of the ICAM-1 gene may not be used as a genetic marker for PCOS .The role of ICAM-1 gene alone as well as in combination with different clinical and laboratory parameters in our study possibly advocates the role of other genetic markers which could be responsible for the development of PCOS, although this cannot be definitively excluded without further analysis in a larger study group combined with analysis of further polymorphisms in the ICAM-1 gene.

\section{Acknowledgements}

This study was supported by the Research Fund of the DST (WOS-A). Project No: SR/WOS-A/LS-642/2012(G).

\section{References}

Asante A, Omurtag K, Stewart EA, Coddington CC (2015). Screening for insulin resistance in polycystic ovary syndrome: views of Physician Members of the American Society for Reproductive Medicine. J Reprod Med, 60 , 371-7.

Azziz R, Woods KS, Reyna R, et al (2004). The prevalence and features of the polycystic ovary syndrome in an unselected population. J Clin Endocrinol Metab, 89, 2745-9.

Blankenberg S, Barbaux S, Tiret L (2003). Adhesion molecules and atherosclerosis. Atherosclerosis, 170, 191-03.

Chou CH, Ueng KC, Liu YF, Wu CH, et al (2015). Impact of intercellular adhesion molecule-1 genetic polymorphisms on coronary artery disease susceptibility in taiwanese subjects. Int J Med Sci, 12, 510-6.

Diamanti-Kandarakis E, Alexandraki K, Piperi C, et al (2006). Inflammatory and endothelial markers in women with polycystic ovary syndrome. Eur J Clin Invest, 36, 691-7.

Flex A, Gaetani E, Angelini F, et al (2007). Pro-inflammatory genetic profiles in subjects with peripheral arterial occlusive disease and critical limb ischemia. J Intern Med, 262, 124-30.

González F, Rote NS, Minium J, et al (2009). Evidence of Proatherogenic inflammation in polycystic ovary syndrome. Metabolism, 58, 954-62.

Hayflick JS, Kilgannon P, Gallatin WM (1998). The intercellular adhesion molecule (ICAM) family of proteins. New members and novel functions. Immunol Res, 17, 313-27.

Hazwanie H, Gan SY (2015). The relevance of genetic polymorphism of CYP1A1, ICAM-1, TNF- $\alpha$ and INSR genes in women with polycystic ovary syndrome (PCOS). J Med Bioengineer, 4, 367-70.

Holder AL, Wolf S, Walshe S, et al (2008). Expression of endothelial intercellular adhesion molecule-1 is determined by genotype: effects on efficiency of leukocyte adhesion to human endothelial cells. Hum Immonol, 69, 71-8

Kanmaz-Ozer M, Vural P, Dogru-Abbasoglu S, et al (2012). Polymorphisms of vascular cell adhesion molecule 1 (VCAM1) in polycystic ovary syndrome determined by quantitative real-time polymerase chain reaction and melting curve analysis. Eur J Obstet Gynecol Reprod Biol, 160, 174-78.

Languino LR, Plescia J, Duperray A, et al (1993). Fibrinogen mediates leukocyte adhesion to vascular endothelium through an ICAM-1-dependent pathway. Cell, 73, 1423-34. 
Lee EJ, Oh B, Lee JY, et al (2008). Association study between single nucleotide polymorphisms in the VEGF gene and polycystic ovary syndrome. Fertil Steril, 9, 1751-59.

Mc Glinchey PG, Spence MS, Patterson CC, et al (2004). The intercellular adhesion molecule-1 (ICAM-1) gene K469E polymorphism is not associated with ischaemic heart disease: an investigation using family-based tests of association. Eur J Immunogenet, 31, 201-6.

Mycko MP, Kwinkowski M, Tronczynska E,(1998). Multiple sclerosis: the increased frequency of the ICAM-1 exon 6 gene point mutation genetic type K469. Ann Neurol, 44, 70-5.

Nasiek M, Kos-Kudła B, Ostrowska Z, et al (2004). Plasma concentration of soluble intercellular adhesion molecule-1 in women with polycystic ovary syndrome. Gynecol Endocrinol, 19, 208-15.

Nejentsev S, Guja C, McCormack R, Cooper J, et al (2003). Association of intercellular adhesion molecule-1 gene with type 1 diabetes. Lancet, 362, 1723-4.

Nidhi R, Padmalatha V, Nagarathna R, et al (2011). Prevalence of polycystic ovarian syndrome in Indian adolescents. $J$ Pediatr Adolesc Gynecol, 24, 223-7.

Ojeda-Ojeda M, Martinez-Garcia MA, Alpanes M, et al (2015). Association of TLR2 S450S and ICAM1 K469E polymorphisms with polycystic ovary syndrome (PCOS) and obesity. J Reproductive Immunol, 113, 9-15.

Petrovic MG, Osredkar J, Saraga-Babic M, et al (2008). K469E polymorphism of intercellular adhesion molecule-1 gene is associated with proliferative diabetic retinopathy in Caucasians with type 2 diabetes. Clin Exp Ophthalmol, 36, 468-72.

Prieto D, Contreras C, Sanchez A (2014).Endothelial dysfunction, obesity and insulin resistance. Curr Vasc Pharmacol, 12, 412-26.

Rosenfield RL (2015). The Diagnosis of Polycystic Ovary Syndrome in Adolescents. Pediatrics, 136, 1154-65.

Salvarani C, Casali B, Boiardi L (2000). Intercellular adhesion molecule 1 gene polymorphisms in polymyalgia rheumatica/ giant cell arteritis: association with disease risk and severity. J Rheumatol, 27, 1215-21.

Shen CC, Yang AC, Hung JH, Hu LY, Tsai SJ (2015). A nationwide population-based retrospective cohort study of the risk of uterine, ovarian and breast cancer in women with polycystic ovary syndrome. Oncologist, 20, 45-9.

Song GG, Lee YH (2015). The polymorphisms K469E and G261R of intercellular adhesion molecule-1 and susceptibility to inflammatory bowel disease: a metaanalysis. Immunol Invest, 44, 361-72.

Springer TA (1990). Adhesion receptors of the immune system. Nature, 346, 425-34.

Urbanek M, Woodroffe A, Ewens KG, et al (2005). Candidate gene region for polycystic ovary syndrome on chromosome 19p13.2. J Clin Endocrinol Metab, 90, 6623-9.

Verity DH, Vaughan RW, Kondeatis E (2000).Intercellular adhesion molecule-1 gene polymorphisms in Behcet's disease. Eur J Immunogenet, 27, 73-6.

Vora DK, Rosenbloom CL, Beaud AL, et al (1994). Polymorphisms and linkage analysis for ICAM-1 and the selectin gene cluster. Genomics, 21, 473-7.

Vrbikova J (2005). Intercellular cell adhesion molecule-1 in PCOS; relation to insulin resistance or obesity. Endocrine Abstract, 9, 76.

Vural P, Kanmaz-Ozer M, Dogru-Abbasoglu S, et al (2011). Lack of association between intercellular adhesion molecule-1 (ICAM-1) polymorphisms and polycystic ovary syndrome. J Assist Reprod Genet, 28, 869-75. 